\title{
Do sagrado ao profano: aproximações entre a teologia cristã e a administração
}

\author{
Aline Van Neutgem ${ }^{1}$ \\ Eloise Helena livramento Dellagnelo ${ }^{2}$
}

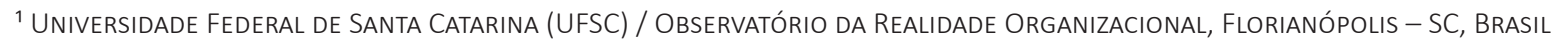

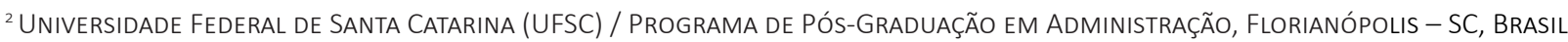

\begin{abstract}
Resumo
Este ensaio teórico procurou realizar uma aproximação entre a administração e a teologia cristã. Para tanto, a partir, principalmente, das ideias de Agamben (2008), procurou-se estabelecer relações entre aspectos relativos à teologia cristã e sua ordem trinitária com as características de organizações burocráticas e flexíveis, no intuito de desvelar a sacralidade e a deidade presente nessas organizações, a despeito da ideia de secularização e racionalidade, no sentido weberiano, impetrada às mesmas. A partir dessas relações e da observação de um novo tipo de sacralização nessas organizações que, sem romper com o ideário divino, tornam sagrado o poder econômico, o dinheiro, a técnica e a lógica formal sobre tudo o mais, advoga-se pela profanação do sagrado. Entende-se que essa saída pode se dar por meio das reflexões acerca da inoperosidade e sua relação com a política e a estética, que remetem a uma nova possibilidade de uso do prazer, do desejo e do corpo.
\end{abstract}

Palavras-chave: Teologia cristã. Burocracia. Organizações flexíveis. Poder. Estética.

\section{From the sacred to the profane: connections between Christian theology and administration}

\begin{abstract}
This theoretical essay aimed to make connections between Christian theology and administration. Starting from the ideas of Agamben (2008), attempts were made to establish relations between aspects of Christian theology and its trinitarian order with the characteristics of bureaucratic and flexible organizations. The intention was to unveil the sacredness and deity in these organizations, despite the idea of secularization and rationality, in the Weberian sense related to them. From these relationships and the observation of a new kind of sacralization in these organizations, which maintains the divine ideology and makes economic power, money, technique, and formal logic sacred over everything else, this essay advocates for the desecration of the Sacred. It is understood that this can take place through reflections about inoperosity and its relationship with politics and aesthetics, which refer to a new possibility of using the ideas of pleasure, desire, and body.
\end{abstract}

Keywords: Christian Theology. Bureaucracy. Flexible organizations. Power. Aesthetics.

\section{De lo sagrado a lo profano: aproximaciones entre la teología cristiana y la administración}

\section{Resumen}

Este ensayo teórico buscó realizar una aproximación entre la teología cristiana y la administración. Para ello, a partir, principalmente, de las ideas de Agamben (2008), se buscó establecer relaciones entre aspectos relativos a la teología cristiana y su orden trinitaria con las características de organizaciones burocráticas y flexibles, con el fin de desvelar la sacralidad y la deidad presente en estas organizaciones, a pesar de la idea de secularización y racionalidad, en el sentido weberiano, atribuida a las mismas. A partir de esas relaciones y de la observación de un nuevo tipo de sacralización en estas organizaciones que, sin romper con el ideario divino, hacen sagrado el poder económico, el dinero, la técnica y la lógica formal sobre todo lo demás, se aboga por la profanación de lo sagrado. Se entiende que esa salida puede darse por medio de reflexiones sobre la inoperosidad y su relación con la política y la estética, que remiten a una nueva posibilidad de uso del placer, del deseo y del cuerpo.

Palabras clave: Teología cristiana. Burocracia. Organizaciones flexibles. Poder. Estética. 


\section{INTRODUÇÃO}

A partir das investigações de Agamben (2008), para o qual a secularização das questões sagradas na modernidade se dá como assinatura, constituindo uma remissão dos conceitos modernos e racionalizados a uma origem teológica, este ensaio teórico buscou realizar uma aproximação entre a teologia cristã e a administração. Assim, procurou-se estabelecer relações entre aspectos relativos à teologia cristã e sua ordem trinitária com as características de organizações burocráticas e flexíveis, no intuito de desvelar a sacralidade e a deidade presente nessas organizações, seja por meio de aspectos formais ou de aspectos gloriosos, sempre cobertos por uma capa de racionalidade e logicidade.

Esta discussão insere-se na esteira de pesquisas que articulam a questão religiosa com os estudos organizacionais, temática que, conforme Tracey (2012), ainda carece de maiores investigações. Dentre as pesquisas já realizadas, pode-se destacar algumas abordagens gerais, tomando como base Tracey (2012) e autores que trabalharam esses assuntos. Neste sentido, observam-se discussões sobre a relação entre organizações religiosas e o contexto em que estão inseridas, refletindo sobre os efeitos de crenças e valores religiosos no ambiente cultural e institucional ou sobre a adaptação de organizações religiosas a uma situação de mercado, usando aportes como a Teoria dos campos, a Teoria do desenvolvimento econômico, a Teoria dos Stakeholders, a Teoria do capital social e a Teoria da escolha racional, dentre outras (COSGEL e MINKLER, 2004; MARTES e RODRIGUEZ, 2004; PARKER e BAKER, 2007; SERAFIM e ANDION, 2010; OLIVEIRA, CORTES e BALBINOTTO, 2011; SERAFIM, MARTES e RODRIGUEZ, 2012; SERAFIM e FEUERSCHÜTTE, 2015; ENOQUE, BORGES e BORGES, 2015; CUNHA, SOUZA, MACAU et al., 2016; BAZANINI e GIGLIO, 2017; CORRÊA, VALE e CRUZ, 2017; BERNARDELLI e MICHELLON, 2018; PAIVA, SOUSA, LIMA et al., 2020; SOUSA, PAIVA, SANTOS et al., 2020).

Há ainda estudos que se concentram na relação entre religião e comportamento individual nas organizações, os quais abarcam questões relativas ao comportamento ético e a valores e atitudes. Utilizam referenciais variados, entre eles Teoria institucional e Psicologia positiva (NELSON, 1993; ASHMOS e DUCHON, 2000; DUCHON e PLOWMAN, 2005; NASCIMENTO, 2005; STEINGARD, 2005; ALBAUM e PETERSON, 2006; KELLER, SMITH e SMITH, 2007; WALKER, SMITHER e DEBODE, 2012; VASCONCELOS, 2015; MARTINEZ e COELHO, 2019). Finalmente, destaca-se também a discussão sobre ideias religiosas em contextos seculares, incorporando estudos que indagam a penetração de ideias e práticas religiosas em outros tipos de organização. Quanto às formas de investigação, algumas dessas pesquisas mobilizam matrizes teóricas como a Análise psicanalítica e a Análise Crítica de Discurso, enquanto outras dialogam com Weber e discussões próprias da Teoria organizacional clássica (PAGÈS, BONETTI, GAULEJAC et al., 1993; PRESTES MOTTA, 2001; ASHFORTH e VAIDYANATH, 2002; FINCH-LEES, MABEY e LIEFOOGHE, 2005; HARRISON, ASHFORTH E CORLEY, 2009).

O presente artigo faz parte dos estudos que Tracey (2012, p. 124, tradução nossa) compreende como "ideias religiosas em contextos seculares", os quais o autor afirma serem importantes porque "põem em causa a clara distinção entre formas organizacionais religiosas e seculares" e porque "ainda temos uma compreensão relativamente rudimentar do papel do sagrado e da dinâmica da sacralização em formas organizacionais". As discussões nesse sentido geralmente abrangem a sociologia da religião, e dela fazem parte variadas abordagens e autores em sua aproximação com a teoria organizacional, desde clássicos como Durkheim, Weber e Marx, até pensadores contemporâneos como Peter Berger, por exemplo, cujas ideias parecem ter certa adesão dentro dos estudos organizacionais.

A leitura de Berger sustenta que não houve secularização como ruptura com a religião, mas sim que existe uma coexistência - com contaminações e barganhas - entre discurso secular e discursos religiosos, ao modo de um pluralismo, em que tais discursos se apresentam aos indivíduos como opções a serem escolhidas. Nessa visão, há esferas institucionais que operam independentemente de valores religiosos, como as trocas comerciais e os aparelhos burocráticos (BERGER, 2017). Outras leituras, como a Ortodoxia radical ou, no campo da administração, a Organização baseada na espiritualidade, também criticam a tese da secularização, mas apontam a espiritualidade como resposta a teorias seculares niilistas representadas por um paradigma material (MILBANK, 1995; VASCONCELOS, 2015).

Nos estudos organizacionais, cabe destacar também as análises críticas a essa ideia de secularização empreendida por Pagès, Bonetti, Gaulejac et al. (1993, p. 76), os quais afirmam que "estamos diante de um sistema religioso, e isto não é uma simples metáfora" e acrescentam que "os valores essenciais da ideologia humanista cristã (...) são alegados para mascarar condições reais de exploração". Para os autores, "esse discurso é fechado, é impossível escapar dele" (PAGÈS, BONETTI, GAULEJAC et al., 1993, p. 85). Nosso artigo compartilha esse diagnóstico, porém está mais afeito aos estudos de Finch-Lees, Mabey 
e Liefooghe (2005), os quais, a partir de investigação discursiva do tema, apresentam as possibilidades de resistência nesse paradigma. Assim, propõe-se como contribuição a essa discussão o aporte do filósofo italiano Giorgio Agamben, ainda pouco trabalhado na administração e cujas investigações no campo da teologia, política e poder podem ser úteis não somente para a problematização de aspectos de organizações burocráticas e flexíveis, mas também para imaginar outras possibilidades de organizar. Conforme Phelps (2012, p. 1, tradução nossa), "a leitura de Agamben da tradição teológica representa um esforço conjunto para profanar essa tradição, para torná-la inoperante para um novo uso".

Contudo, é importante salientar que a presente proposta não teve por objetivo encerrar uma remissão dessas organizações à sua originalidade divina ou a um modelo teológico específico. Não ignoramos que haja outras relações e origens que possam influenciar suas formas de organizar e as relações de poder e dominação que as perpassam, já apontadas por trabalhos que discutem a passagem da forma burocrática à flexível muito mais como adaptação do que como ruptura (PAES DE PAULA, 2002; SILVA, 2003; BÖHM, 2005; PALMER, BENVENISTE e DUNFORD, 2007). Deste modo, objetivou-se, certamente, jogar luz sobre as possíveis relações e remissões existentes entre a organização oikonómica divina e as organizações burocráticas e flexíveis, procurando compreender as implicações dessa origem na cristalização de práticas de sujeição e subjetivação do interior dessas organizações.

Nas seções que seguem, procurou-se problematizar a noção de secularização weberiana, recorrentemente trabalhada no âmbito dos estudos organizacionais, bem como resgatar aspectos relativos à burocracia e às organizações flexíveis, procurando sinalizar sua identificação com elementos sagrados. Ao final, a partir da análise remissiva realizada, fazem-se algumas reflexões e apontamentos acerca da possibilidade de interrupção desse novo sacrário, que é o império do poder econômico, da técnica e da razão sobre toda forma de organizar a sociedade e a vida humana, por meio da articulação da noção de inoperosidade e sua relação com a política e a estética, que remetem a uma nova possibilidade de uso do prazer, do desejo e do corpo.

\section{SECULARIZAÇÃO COMO ASSINATURA}

Max Weber, importante teórico da sociologia e grande influenciador do pensamento administrativo, dedicou-se a estudar o "processo de racionalização da esfera da religião, da moral, do direito, da arte, da economia, da política, etc.", procurando demonstrar que houve, na idade moderna, um rompimento com o tradicionalismo e com a "organização social fundada na santidade da tradição" (RAMOS, 2006, p. 271-272). Ainda conforme Ramos (2006), para Weber, a ratio é, por excelência, o instrumento da secularização, aquilo que torna possível erradicar o medo do sagrado. A secularização seria, portanto, no sentido weberiano, um processo de crescente desencantamento e desteologização do mundo moderno.

Para realizar as aproximações entre teologia cristã e administração pretendidas no presente ensaio teórico, faz-se necessário esclarecer, preliminarmente, o sentido e as implicações que o termo secularização engendra. Segundo Agamben (2008), o conceito de secularização desempenhou uma função estratégica na cultura moderna, tanto em seu sentido estritamente jurídico quanto em seu emprego metafórico na história das ideias. Para Agamben (2008, p. 17, tradução livre), "quando Max Weber formula sua célebre tese sobre a secularização do ascetismo puritano na ética capitalista do trabalho, a aparente neutralidade de seu diagnóstico não pode esconder sua função de batalha pelo desencantamento do mundo" que Weber opõe aos fanáticos e falsos profetas.

Mais tarde, um outro intelectual alemão, Carl Schmitt, propõe um debate acerca da secularização em termos distintos de Weber. Conforme Agamben (2008, p. 19-20, tradução livre), no centro desse debate estava a tese de que "tanto a filosofia da história do idealismo alemão como a ideia de progresso do lluminismo não são outra coisa senão uma secularização da teologia da história e da escatologia cristã", o que se coaduna com as teorias de Hegel, que "estava perfeitamente consciente disso quando afirmava a equivalência entre sua tese sobre o governo racional do mundo e a doutrina teológica do plano providencial de Deus, e apresentava sua própria filosofia da história como uma teodiceia". Neste sentido, é possível observar que a concepção de Schmitt é inversa à de Weber. Para Schmitt, a estratégia de secularização atesta que a teologia ainda está presente e atua de modo iminente no mundo moderno, e não que houve um rompimento com a tradição da santidade. É preciso asseverar, no entanto, que isso não implica "uma perfeita identidade de significado entre conceitos teológicos" e modernos; "é, antes, uma relação estratégica particular", que marca tais conceitos "referindo-os à sua origem teológica" (AGAMBEN, 2008, p. 17-18). 
Entendida dessa forma, como relação estratégica que faz remissões à origem teológica dos conceitos políticos no período moderno, a secularização não representa um conceito, mas sim uma assinatura, no sentido encontrado em Foucault e Melandri. As assinaturas possuem um caráter genuinamente histórico, na medida em que constituem uma rede de remissões e citações temporais que não cessam. Representam, assim, o outro no mesmo, o velho que se faz novo a cada enunciação, em uma (re)organização e (re)articulação de discursos, sem com isso constituir um novo significado ou conceito (FOUCAULT, 1996). Em outras palavras, as assinaturas deslocam conceitos de uma esfera para outra sem, com isso, redefini-los semanticamente. A secularização, portanto, atua no sistema conceitual moderno como uma assinatura que faz remissão temporal à teologia, denotando na modernidade um pertencimento à oikonomía divina (AGAMBEN, 2008). Este ensaio teórico, que tem como objetivo realizar uma aproximação entre a teologia cristã e a administração, procurando demonstrar que a dinâmica religiosa cristã possui estreita relação com a dinâmica econômica e administrativa, alinha-se a esse entendimento de secularização.

Nesta mesma linha, Adorno e Horkheimer $(1985$, p. 6) afirmam que o programa do esclarecimento, isto é, da secularização, o qual consistia no desencantamento do mundo e na superação das explicações metafísicas fundadas em deuses, inculcou uma nova metafísica, pautada na lógica formal, ordenadora. Segundo os autores, a razão técnica torna-se essência do saber moderno, "que não visa conceitos e imagens, nem o prazer do discernimento, mas o método, a utilização do trabalho de outros, o capital". Desta forma, Adorno e Horkheimer $(1985$, p. 6) informam que "enquanto soberanos da natureza, o Deus criador e o espírito ordenador se igualam", pois "os mitos que caem vítimas do esclarecimento já eram o produto próprio do esclarecimento". Neste sentido, em lugar da sacralização de um Deus ocorre uma nova sacralização: do poder econômico, do dinheiro, da razão técnica e da lógica formal.

Se isso é verdade, todos os conceitos decisivos da ciência moderna são conceitos teológicos secularizados, isto é, revestidos da razão moderna, mas originários da teologia. Conforme Agamben (2008, p. 16, tradução livre), "essa afirmação [anterior] deveria ser completada em um sentido que estenderia sua validez para além dos limites do direito público, até implicar os conceitos fundamentais da economia" e da vida em sociedade. Para o filósofo italiano, a oikonomía dos modernos, assumindo uma soberania separada de sua origem divina mantém, na realidade, o modelo teológico de governo do mundo.

Neste sentido, ao observar a burocracia como expressão organizacional de um tipo de pensamento e sociedade racionalizados, não se pode ignorar a deidade ainda presente nas formas de organização da sociedade moderna. Como será discutido adiante, a própria burocracia e, mais tarde, as chamadas organizações flexíveis retomam ou preservam em grande parte elementos da teologia cristã e aspectos de sua administração divina. Para Agamben (2008, p. 497, tradução livre), ocorre uma identificação na imagem do mundo com e sem Deus: "contingência e necessidade, liberdade e servidão se fundem uma na outra". Nesta espécie de ambivalência categorial, "a modernidade, retirando Deus do mundo, não só não saiu da teologia, como, em certo sentido, não fez mais do que levar a cabo o projeto da oikonomía providencial". Em outras palavras, a razão, na modernidade, cumpre a função de manter incólume uma determinada ordenação do mundo, mas agora sob a égide da lógica formal e da economia moderna.

Assim, segundo Nietzsche (2001), mesmo após a morte de Deus, suas sombras ainda recaem sobre os homens. Para o filósofo, a ciência moderna finge abolir Deus, porém reintegra suas sombras - a crença em um mundo racional, as leis puras da lógica, o cosmos governado por um logos, etc. - por meio do racionalismo filosófico e da crença na ciência, variações da antiga ordem religiosa e moral. Novos dizeres habitam, agora, a esfera do sagrado, constituindo-se em outros axiomas, afirmações universais e intocáveis. De acordo com Souto (2011, p. 134), para Nietzsche, "o cristianismo teria estendido a doutrina platônica dos dois mundos ao povo, convertendo seus valores filosóficos em valores morais (...). Com o cristianismo, portanto, se erigiu uma moral da negação dos valores vitais e uma degeneração da vida". Essa degeneração da vida é levada às últimas consequências na sociedade capitalista, na qual o ser é moldado a partir da manipulação e da administração. Partindo dessas teorizações, procura-se realizar algumas aproximações entre a teologia cristã e a administração, demonstrando a secularização como assinatura de aspectos sagrados nas práticas e no pensamento administrativo concernente às organizações burocráticas e, depois, de modo mais sofisticado, nas organizações flexíveis, uma vez que estas últimas não realizam uma ruptura com aspectos fundacionais das primeiras (PAES DE PAULA, 2002; SILVA, 2003; BÖHM, 2005). 


\section{APROXIMAÇÕES ENTRE A ADMINISTRAÇÃO E O SAGRADO}

De acordo com Bédard (2004), o sagrado é histórico e contextual e designa aquilo que o homem considera como poderes positivos e negativos em determinada esfera, ou aquilo que é digno de respeito. Deste modo, investigar as aproximações entre a administração e o sagrado se torna uma tarefa crucial para melhor compreender as práticas e o pensamento administrativo, bem como as relações de poder, dominação, submissão e governamento (ou pastorado) que os envolvem. Para Agamben (2008, p. 91, tradução livre), a teologia cristã exerce forte influência no pensamento e na organização social do Ocidente e, longe de ser apenas um "relato sobre os deuses", é "imediatamente economia e providência, isto é, atividade de autorrevelação, governo e cuidado do mundo". A divindade cristã articula-se por meio de uma Trindade ${ }^{1}$ (pai, filho e espírito santo), que não é uma teogonia ou uma mitologia, mas sim uma oikonomía, ou seja, uma articulação e uma administração da vida divina e governo das criaturas.

Bédard (2004, p. 101) explora o lado sagrado da administração - ou o lado administrativo do sagrado - ao argumentar que

En tanto representante oficial y exclusivo de lo sagrado ye de los valores, el dirigente, cualquiera que sea su nivel jerárquico, es una suerte de "gran sacerdote" que preside en toda especie de ritos: representaciones y ceremonias oficiales, sanción y promulgación de los textos oficiales, recepción de los visitantes destacados y toda una serie de actividades emblemáticas y protocolarias.

No trabalho de Agamben (2008), também há evidências da relação entre administração e sagrado por meio de uma oikonomía divina. Segundo o autor, o evangelho de Paulo não apenas se refere a uma oikonomía de Deus como também se refere a ele mesmo e aos membros da comunidade messiânica com termos que pertencem exclusivamente ao vocabulário da administração doméstica: doûlos ("escravo"), hyperétes, diákonos ("criado"), oikonómos ("administrador"). Ocorre, portanto, uma estreita relação, desde muito, entre administração e teologia cristã, na medida em que a própria origem do termo está imbricada com a religião. Para o autor, pode-se falar em uma espécie de paradigma teológico da administração, que encontra seu exemplo perfeito nas hierarquias angélicas, que serão exploradas adiante.

Ao tratar da restituição da oikonomía enquanto governo dos homens, o que envolve a administração de um organismo social complexo, permeado por diversas relações, Agamben (2008, p. 81-82, tradução livre), recupera as origens do termo administração. Conforme o autor, "a definição do conceito jurídico-político de 'administração' sempre foi problemática para os historiadores do direito e da política", que localizaram a origem do termo no direito canônico dos séculos XII e XIV, "quando o termo administratio começa a se aproximar de jurisdictio na terminologia dos canonistas".

A noção de oikonomía é importante, aqui, porque ao instituir uma oikonomía trinitária, hierarquizada, a teologia cristã distribuiu de certa forma o poder, mas sem dividir a unidade central. Os membros da hierarquia trinitária, investidos de frações de poder divino para a realização de suas tarefas, glorificam e reforçam, de certo modo, a figura de poder original. Outra questão importante é que a noção de oikonomía é extremamente valiosa e se coaduna com o objetivo teológico porque promove um escamoteamento do político. Essas duas questões centrais - a aparente distribuição de poder e o escamoteamento político - são também fundamentais, como será abordado adiante, na compreensão das dinâmicas organizacionais da burocracia e das organizações flexíveis.

\footnotetext{
${ }^{1}$ A questão da Trindade na teologia cristã permanece polêmica, sendo discutida por teóricos como Carl Schmitt, que trazem a transcendência para a imanência e vice-versa, ou como Erik Peterson, que sugerem a separação definitiva entre imanência e transcendência. Agamben parte de Carl Schmitt e compreende que "a fratura originalmente exposta entre transcendência e imanência, advinda do aristotelismo, é ressignificada pela teologia cristã, de modo que o Deus cristão é esse em que ordem transcendente e ordem imanente relacionam-se mutuamente, passando de uma para a outra" (PFISTER, 2019, p. 53). Agamben (2008, p. 102) coloca a questão nos seguintes termos: "se levarmos ao extremo o paradigma da substância separada, temos gnose, com seu Deus estranho ao mundo e à criação; se seguimos até as últimas consequências o paradigma da imanência, temos o panteísmo. Entre esses dois extremos, a ideia de ordem procura pensar um equilíbrio difícil, do qual a teologia cristã está sempre a cair e o qual a cada vez ela deve reconquistar". Gregório de Nissa, um teólogo capadócio, é quem tenta estancar a cisão do ser de Deus e sua práxis, sinalizando que "Deus seria uno na sua substância e trino em sua economia, sem qualquer ruptura da comunhão" e, mesmo se diferenciando em número, não se dividiria quanto à substância (PFISTER, 2019, p. 42). É essa dualidade - entre Trindade imanente e econômica - marcada por uma série de divisões complementares em cujo centro está a Glória que, para Agamben (2008), permite o funcionamento da máquina governamental divina sobre os homens no mundo.
} 
Ainda no que se refere à oikonomía ou administração divina, Agamben (2008, p. 41-42) esclarece que a noção resgata o pensamento aristotélico e adverte que

Oikonomia significa "administración de la casa". En el tratado aristotélico (o pseudoaristotélico) sobre la
economía, se lee que la téchne oikonomiké se distingue de la política, como la casa (oikía) se distingue
de la ciudad (pólis). [...] Es preciso no olvidar, sin embargo, que el oikos no es la casa unifamiliar moderna
ni simplemente la familia ampliada, sino un organismo complejo en el que se entrelazan relaciones
heterogéneas, que Aristóteles (Pol., 1253b 1-10) distingue en tres grupos: relaciones "despóticas"
patrón-esclavos [...], relaciones "paternales" padre-hijos, relaciones "conyugales" marido-mujer. Lo que
une estas relaciones "económicas" [...] es un paradigma que podríamos definir "de gestión" [...]: ella no
tiene que ver sólo con la necesidad y el uso de los objetos, sino ante todo con su disposición ordenada.

A disposição ordenada, que conforma uma espécie de harmonia em que se camufla a questão do conflito, da luta e da tensão presentes nessas relações heterogêneas que se entrelaçam, também é um elemento importante para a manutenção da oikonomía e da gestão, na medida em que apenas o deslocamento de uma racionalidade política para uma econômica seria capaz de proteger a organização divina contra o perigo de uma stasis interna (AGAMBEN, 2008).

Como se pode perceber, a oikonomía caracteriza-se aqui como uma organização funcional, como uma atividade de gestão que exerce um governo dos homens e não está vinculada a outras regras que não as do funcionamento ordenado da "casa" ou da organização em questão. É este paradigma de gestão, nas palavras de Agamben (2008, p. 43-44, tradução livre), que "define a esfera semântica do termo oikonomía e (...) determina a sua progressiva extensão analógica para além de seus limites originais".

Se é, conforme Agamben (2008), uma ordem sagrada que influencia a constituição da organização da sociedade sob um paradigma de gestão, pode-se pensar agora que é a própria gestão que, com contornos de racionalidade técnica e lógica formal, torna-se sagrada em nosso tempo. A naturalização da gestão pautada em uma racionalidade formal como a única forma correta e possível de administrar organizações reforça, por certo, convenções sociais que sustentam formas assimétricas de poder. Nesse projeto, a que alguns autores chamam managerialismo ou gerencialismo, o próprio posicionamento de uma ideia de organização moderna e suas teorias organizacionais correlatas contribui, em muito, para estimular técnicas que perpetuam o ideário da organização moderna (TRAGTENBERG, 2005; PAES DE PAULA, 2002; PARKER, 2002; BÖHM, 2005; IBARRACOLADO, 2006; FARIA e MENEGHETTI, 2011; SPICER, ALVESSON e KARREMAN, 2009, 2016). Essa ideia - que argumentamos ser substancialmente teológica - de uma ordem natural das coisas e sujeitos, de suas posições e seu destino no mundo, contribui para perpetuar injustiças e manter um desenraizamento político dos sujeitos em relação ao seu contexto social.

\section{ORGANIZAÇÕES BUROCRÁTICAS E ANGELOLOGIA}

No intuito de trazer luz à conexão entre a administração e a teologia cristã, faz-se nesse ensaio uma aproximação entre características de organizações burocráticas e flexíveis com as características da administração divina. Nesta seção, apresenta-se essa relação envolvendo as organizações burocráticas, as quais herdam muitos aspectos teológicos, trazendo essa discussão mais para perto da literatura sobre teoria organizacional.

Conforme argumenta Böhm (2005, p. 4, tradução nossa), "a visão que temos do mundo não é do mundo em si, mas é uma visão baseada em um regime organizacional particular de técnicas modernas". Segundo o autor, esse regime organizacional relaciona-se com a modernidade e com o capitalismo, momento em que as coisas passam a ser colocadas em um lugar definido e seguro, encerrando noções construídas como uma forma neutra e correta daquilo que pretendem significar. Assim, na modernidade, a noção de organização é construída e posicionada como organização burocrática, a qual está relacionada à administração e manutenção de um mundo ordenado tecnicamente e caracterizado por divisões claras de trabalho e por corpos racionais que podem ser ordenados e mensurados.

De acordo com Prestes Motta (1991), o termo "burocracia" tem sido empregado em vários sentidos: para designar uma administração racional e eficiente - ou o contrário, um governo de funcionários ou mesmo a própria organização. Conforme o autor, a burocracia é tudo isso, uma vez que é poder, controle e alienação. Segundo Faria e Meneghetti (2011), o aspecto do poder expressa-se na burocracia por meio das relações de dominação existentes nesse tipo de organização, as quais são 
capazes de perpetuar posições sociais e formas de dominação política e econômica baseadas em uma lógica racional-legal. Como controle, a burocracia consegue estabelecer relações de domínio por vias objetivas ou pelo domínio intersubjetivo (em que há um importante fator ideológico), lançando mão de variados dispositivos ${ }^{2}$ como a tecnologia, os códigos, os procedimentos e o próprio imaginário. Por fim, como alienação, a burocracia age de modo a fazer com que o indivíduo interiorize o modo burocrático de pensar, sentir, agir, pois como explicam Faria e Meneghetti (2011, p. 434), "a inculcação ideológica, a submissão, os comportamentos padrão e o disciplinamento não são decorrentes apenas da forma objetiva como a burocracia se institui na organização".

Esses três aspectos determinantes da burocracia - poder, controle e alienação - perpassam os elementos do tipo ideal burocrático, descritos por Weber. Em elementos como o formalismo, a impessoalidade e a hierarquia, é possível observar o poder, o controle e a alienação subjacentes (PAES DE PAULA, 2002). Para nós, essas características são extremamente úteis para realizar o exercício de refletir sobre as possíveis remissões de aspectos teológicos nas burocracias, que se sucedem em uma plataforma de trabalho racionalizado, dividido e desqualificado (TRAGTENBERG, 2005; FARIA e MENEGHETTI, 2011). A burocracia, organização moderna que se forja no processo de esclarecimento, de rompimento com o sagrado, com a deidade, com a filosofia escolástica e todas as explicações metafísicas, constitui, argumentamos, uma assinatura que nos remete à teologia. Sua estrutura, no formalismo e na hierarquia, assemelha-se à angelologia ${ }^{3}$ cristã, na qual estão preservadas as questões sensíveis do poder, do controle e da alienação, como procura-se refletir a seguir.

A burocracia moderna funciona sob formas específicas, caracterizadas, por exemplo, por estarem

sob a regência de áreas de jurisdição fixas e oficiais, ordenadas por leis e normas administrativas. Ela estabelece relações de autoridade, delimitada por normas relativas aos meios de coerção e de consenso. Uma relação hierárquica se estabelece, definindo postos e níveis de autoridades, além de um sistema de mando e subordinação com gerência das atividades e tarefas delegadas por autoridade. Nesse contexto, a administração é formalizada por meio de documentos, que acabam por regular a conduta e as atividades das pessoas (FARIA e MENEGHETTI, 2011, p. 427, grifo nosso).

Essa ordenação formalizada por normas que regulam a conduta e as atividades dos indivíduos, assim como a relação hierárquica que se estabelece definindo níveis de autoridade e a dinâmica do sistema de mando, faz remissão à organização da administração divina na teologia cristã, que possui a mesma estrutura funcional expressa em uma ordem trinitária econômica. Com uma hierarquia vertical bem delimitada por variadas funções administrativas e diferentes artifícios de orientação da vida divina e terrena, a exemplo dos mandamentos e dos evangelhos, a oikonomía divina administra os indivíduos que se relacionam heterogeneamente na oikós.

Para ilustrar o aspecto econômico da administração mobilizada na ordem trinitária cristã, Agamben (2008, p. 83, tradução livre) "evoca a angelologia como paradigma teológico da administração, instituindo, com um movimento quase kafkiano, uma correspondência entre anjos e funcionários" na forma de organizar e distribuir - ou não - o poder. Esse paralelismo entre a hierarquia angélica e a hierarquia burocrática pode ser ilustrado pela imagem da escada de Jacó, encontrada no livro Gênesis do Antigo Testamento e retratada pelo pintor e poeta William Blake em 1805:

Las operaciones angélicas se reducen a dos: la operación contemplativa y la ministerial [...] Y a través de estas dos se distinguen los espíritus angélicos y sus operaciones. La contemplativa consiste en una ascensión a las cosas supremas, la administrativa en el descenso a las cosas humanas. Ambas se tocan en la escalera, donde los ángeles suben y bajan... (AGAMBEN, 2008, p. 261).

Na passagem anterior, é possível observar que há, nas hierarquias angélicas, uma separação entre anjos que realizam operações contemplativas, relativas à interpretação do mistério divino, e anjos que realizam operações ministeriais, administrativas, relativas às tarefas manuais. Essa separação permanece como assinatura nas organizações burocráticas, pois, como afirmam

\footnotetext{
${ }^{2}$ Os dispositivos, que são todas as coisas que possuem "de algum modo a capacidade de capturar, orientar, determinar, interceptar, modelar, controlar e assegurar os gestos, as condutas, as opiniões e os discursos dos seres viventes" contribuem para perpetuar e naturalizar o comportamento dos indivíduos segundo preceitos hegemônicos (AGAMBEN, 2009, p. 40-41). Conforme Agamben, não somente as instituições (escolas, manicômios, igrejas, fábricas, etc.), cuja conexão com o poder é num certo sentido evidente, mas também a caneta, a escritura, a literatura, a tecnologia, etc., possuem, de algum modo, a capacidade de moldar o comportamento humano. Assim, o modelo organizacional próprio dessa oikonomía moderna, isto é, a burocracia, opera um processo de adestramento da alma dos indivíduos.

${ }^{3}$ Ramo da teologia que estuda os anjos relativamente à sua natureza e suas funções.
} 
Faria e Meneghetti (2011) e Prestes Motta (1991), há na burocracia uma separação taylorista entre trabalho intelectual e manual. Interessante notar que o próprio Taylor vem de uma família muito rígida e puritana, o que se reflete em sua administração científica, emocionalmente inerte e altamente formal.

Agamben (2008) faz um adendo sobre essas separações hierárquicas ao afirmar que todos os anjos podem ver a divina essência, mas apenas os de grau superior são capazes de compreender os segredos e mistérios divinos, e são estes os anjos que transmitem os segredos - como revelação - aos anjos inferiores. Esse aspecto corrobora a descrição de Weber segundo a qual a burocracia, por meio de sua hierarquia, "potencializa os segredos, os conhecimentos e as intenções", tendendo para "uma estrutura organizada de pequenas sessões secretas, na medida em que oculta conhecimentos e ações" (FARIA e MENEGHETTI, 2011, p. 427).

É preciso salientar que esse princípio hierárquico próprio das funções angélicas é elevado a lei universal, implicando também as hierarquias civis, como pode ser observado na esfera social e na burocracia em que há uma clara divisão das funções e das posições ocupadas. A divisão do trabalho, argumenta Tragtenberg (1974), tem amplas implicações culturais, ideológicas e políticas porque retira dos trabalhadores a compreensão do processo como todo, fragmentando sua consciência. $\mathrm{O}$ autor acrescenta que é a estrutura burocrática que garante a obediência às ordens e sedimenta essas separações entre tipos de trabalho e tipos de trabalhadores, uma vez que "as pessoas alienam-se nos papéis e estes se alienam no sistema burocrático." (TRAGTENBERG, 1974, p. 196). Neste sentido, verifica-se a centralidade da hierarquia e da ordenação nesse paralelo entre administração divina e burocrática e, assim, anjos e burocratas tendem a se confundir, como num universo kafkiano:

no sólo los mensajeros celestes se disponen según oficios y ministerios; también los funcionarios terrenales adquieren a su vez semblantes angélicos y, como los ángeles, se vuelven capaces de purificar, iluminar y perfeccionar. [...] En todo caso, lo decisivo es que mucho antes de que empezara a elaborarse y establecerse la terminología de la administración y el gobierno civil, esta ya estaba firmemente constituida en el ámbito de la angelología. Como hemos visto, no solo el concepto de jerarquía, sino también los de ministerio y misión encuentran una primera y articulada sistematización de las actividades angélicas (AGAMBEN, 2008, p. 276-277).

Deste modo, é por meio de leis, normas, mandamentos e códigos, com função documental e, num certo sentido, jurídica, que a ordenação divina segundo uma hierarquia angélica se mantém, o que denota conexão evidente com os aspectos da burocracia moderna. Esse formalismo na esfera teológica cristã se dá sob a forma de "consagração". De acordo com Ludueña Romandini (2011, p. 104-105, tradução livre), mediante um sacramento - que vale como lei - se consagra a entrada no mundo sagrado: "a própria entrada na Igreja cristã se dá por um ato sacramental que consiste na inclusão - pelo batismo de um novo membro". Aqui, pode ser feita uma analogia com o processo de ingresso de um indivíduo em uma organização burocrática: por meio de um contrato, que consagra o indivíduo como membro daquela organização, inicia-se um rito de educação e disciplina de seu corpo, de suas vontades e ações.

Além disso, a partir daí o indivíduo passará por uma série de processos de socialização para adequar sua personalidade à personalidade burocrática. Conforme Prestes Motta (1978, p. 71), "espera-se desses indivíduos lealdade, um comportamento racionalmente de acordo com critérios técnicos e profissionais, e deferência à autoridade dos altos dirigentes", o que "pressupõe um processo de acomodação pelo qual determinados valores são inculcados nos indivíduos, ocorrendo assim um processo de socialização intra-organizacional". Para Ludueña Romandini (2011, p. 106, tradução livre), na teologia cristã, "o sujeito consagrado transmuta sua própria substância ontológica" a partir de seu ingresso na hierarquia celestial, e "esse caráter sacramental aliena o sujeito de qualquer laço íntimo com o mundo terreno que, no entanto, deverá habitar, na qualidade de estrangeiro, durante todo o transcurso de sua vida".

Assim ocorre também com o sujeito socializado no interior da burocracia, o qual, por meio de treinamentos alienantes, torna-se não mais do que um ocupante de cargo. Por meio da educação (na teologia com os sermões, cultos, catequeses, e na burocracia pelos treinamentos e orientações individuais e coletivos), a personalidade moldada nos sujeitos preconiza a obediência, a resistência à frustração, a capacidade de adiar recompensas e o desejo permanente de realização, características essenciais para a manutenção da dominação e da assimetria de poder presente nas hierarquias, sejam celestiais ou burocráticas (PRESTES MOTTA, 1981).

Esses processos de socialização também são importantes, segundo Faria e Meneghetti (2011, p. 427), porque transformam o trabalho em profissão, tornando-o impessoal, e favorecem que atividades estáveis possam ser aprendidas por todos. 
Por conta dessa impessoalidade, "a posição pessoal de um funcionário é desfrutada e estimada em um contexto social específico, sempre em comparação aos demais funcionários e em relação à estrutura social". A impessoalidade, como atributo da burocracia, faz remissão ao exercício impessoal de poder já presente na teologia sacramental cristã durante a Idade Média. Explica Ludueña Romandini (2011, p. 108):

Como ya señalaban los tratados medievales sobre los sacramentos, aún si el funcionario está desprovisto de fe, mientras realice el acto formal externo, su acción será válida. Por ello, ya sea que un ministro odie a la Iglesia o le sea del todo indiferente en su fuero interior (como en el ejemplo de Max Weber), la acción burocrática es completamente eficaz puesto que su fuerza proviene del poder espiritual (o, en su versión secularizada, de la ley) que instituye al funcionario como tal y no del mundo ético o de su fuero interior.

Por fim, o controle social desenvolve-se na organização burocrática como instrumento de manutenção da ordem e da aparente harmonia social, obtida por meio de um escamoteamento político e da neutralização do conflito (PAES DE PAULA, 2002; BÖHM, 2005). O controle constitui um instrumento de poder e dominação e designa a avaliação e o julgamento de funcionários superiores em relação a funcionários inferiores com base na lei interna. É assim também na teologia, onde a confissão cumpre o papel de investigação, por parte do funcionário superior (como o sacerdote, por exemplo) das atividades, das vontades e das ações dos indivíduos em funções inferiores hierarquicamente. Essas informações são, do mesmo modo, confrontadas com a escritura e o mandamento sagrado, resultando em punições ou recompensas (não necessariamente materiais). Mais uma vez, observa-se uma remissão da burocracia à teologia como conceito ou prática teológica secularizada no sentido de sua assinatura.

\title{
AS ORGANIZAÇõeS FLEXÍVEIS, A GLÓRIA E O PASTORADO
}

\author{
"Dios gobierna todo de modo irresistible, pero dulcemente y sin violencia, \\ de manera que el hombre cree seguir su voluntad mientras ejecuta la de Dios"
}

(Gottfried Wilhelm Leibniz).

Conforme Clegg (1998), é principalmente a partir da década de 1980 que começam a surgir formas de organização diferentes e questionadoras do modelo burocrático como a maneira mais eficiente de organizar o trabalho - são as chamadas organizações pós-modernas. Alguns autores, no entanto, discordam de que essas organizações sejam essencialmente diferentes das burocráticas, como Thompson (1993), por exemplo. Para o autor, há que se considerar que elementos enfatizados como típicos de modelos burocráticos de organização - o cálculo de consequências, a busca por previsibilidade, etc. - não parecem ter sido abandonados. Essa conclusão encontra eco no trabalho de Paes de Paula (2002, p. 137-138), no qual a autora afirma que a desburocratização é uma falácia e que, na verdade, "trata-se de uma operação ideológica, que oculta novas relações de poder e dominação".

As organizações pós-modernas ou flexíveis "representam uma adequação das teorias e práticas ao capitalismo flexível" (PAES DE PAULA, 2002, p. 136) e se caracterizam por: enfatizar uma tomada de decisão mais frequente e rápida; abolição de controles rígidos; flexibilização dos horários e das formas de trabalho; a contínua aquisição de informação; o empowerment; a distribuição de informações mais direcionada; a liderança mais carismática e o melhor gerenciamento da aprendizagem organizacional (HUBER e GLICK, 1995; GREY e GARSTEN, 2001). Deste modo, nesse novo tipo de organização, a centralização, a hierarquia vertical, a autoridade baseada em regras, a disciplina e a divisão do trabalho, aspectos característicos das burocracias, dão lugar à descentralização, à conexão pela tecnologia de informação, à liderança facilitadora e ao trabalho baseado na cooperação. Paes de Paula (2002, p. 138-139) explica que "a burocracia reinventou a hierarquia e sofisticou os mecanismos de controle, tornando suas tentativas de harmonização das tensões entre capital e trabalho ainda mais disfarçadas, reduzindo as possibilidades de emancipação humana na esfera das organizações".

Silva (2003) assevera que as organizações pós-modernas, que disfarçam oferecer mais autonomia aos seus membros do que em modelos burocráticos, têm potencial de promover um controle ainda mais insidioso, como um punho de ferro em luva de pelica. Pagès, Bonetti, Gaulejac et al. (1993) já sinalizaram para o domínio ideológico das organizações flexíveis, identificando-as com os mecanismos fundamentais dos sistemas religiosos. Neste sentido, não apenas não há cisão com o 
modelo burocrático como ocorre, ainda, uma remissão de aspectos teológicos. Contudo, nas organizações pós-modernas, a conexão com o sagrado refere-se menos à estrutura e mais aos aspectos simbólicos e da Glória ${ }^{4}$. Do mesmo modo que na Trindade cristã, em que Deus apresenta-se uno em sua substância e trino em sua economia, sem que com isso ocorra qualquer ruptura de comunhão, nas organizações flexíveis também é possível identificar que o empowerment, ou aparente distribuição de autoridade, longe de significar a dissolução de um poder central, reforça e legitima assimetrias de poder: a economia glorifica o ser e o ser glorifica a economia (SILVA, 2003; AGAMBEN, 2008; PFISTER, 2019).

Assim, há sempre uma figura una, ou divina, que direciona o fazer, ainda que implicitamente, mesmo em um ambiente onde a hierarquia formal se dissolve. É esse "uno", essa figura subjetiva de poder, que abranda os conflitos e harmoniza o conjunto. O próprio conjunto, que nas organizações flexíveis aparentemente se sobrepõe a uma figura de liderança única, acaba por legitimar os donos do poder que, de fato, não foi distribuído. Segundo Agamben (2008, p. 77, tradução livre), também a oikonomía divina se constitui como uma "economia da harmonia [oikonomía symphonías]" a qual, a despeito de seu conjunto de membros que desempenham funções diversas e possuem frações de poder, "termina em um só Deus".

A aparente ausência da figura de controle não implica que não haja, nas organizações flexíveis, vigilância e mando, que passam a ocorrer de modo mais sofisticado (SILVA, 2003). Conforme Tragtenberg (2005, p. 26-28), mesmo nas estruturas empresariais "despidas de formalismo rígido, o subordinado mantém diante de seus superiores um temor reverencial ambivalente, o medo funda-se na agressividade e na sedução, excluindo a neutralidade afetiva". Para o autor, o controle se dá nessas organizações de modo mais simbólico e subjetivo, na medida em que executivos treinados procuram intervir no plano humano e social por meio de uma "literatura moralizante com colóquios e seminários que mostram como os executivos estão preocupados em criar um papel semimissionário na organização". Neste sentido, os “inquisidores modernos", nas palavras de Tragtenberg, estão convencidos de que sua mensagem carrega uma verdade, mais ou menos como a verdade única e divina, objeto dos missionários cristãos.

Ainda segundo Tragtenberg (2005, p. 31), a organização que procura difundir o participacionismo como forma de substituição às hierarquias rígidas mantém incólume o princípio da autoridade uma vez que, inspiradas em padres e psiquiatras, descobre que a técnica da não-diretividade é muito mais eficaz no controle humano do que os interrogatórios e outras medidas sistemáticas e coercitivas. Ocorre, neste sentido, uma domesticação do indivíduo pela empresa, e esta última aparece como "o novo sacrário, fornece a segurança, o apoio e os conselhos das igrejas antigas, só que o novo clérigo é o administrador".

Nossas próprias concepções de autoridade reproduzem uma lógica calcada em representações sociais, geralmente inconscientes. Partindo das ideias de Tragtenberg (2005) e Agamben (2008), pode-se problematizar a figura do chefe "nato" ou do vendedor "nato", por exemplo, em que certas pessoas possuiriam certa vocação superior ou estariam predestinadas a comandar ou obedecer, mesmo em uma relação de aparente horizontalidade, em que alguns indivíduos "naturalmente" se destacam em certo sentido. No entanto, essa ordenação natural dos indivíduos, divididos em senhores e servos, não é natural, mas sim expressa uma ordenação divina do mundo de acordo com critérios misteriosos como a vocação e a predestinação.

Com a horizontalização da estrutura nas organizações flexíveis, a figura física do poder sai de cena, gerando uma espécie de "trono vazio". Moltmann (2000, p. 170) esclarece que no pós juízo divino, quando se der a cessação de toda atividade oikonómica, isto é, "quando tudo estiver 'em Deus' e 'Deus for tudo em todos' (...) O que permanecerá é o eterno hino de louvor do Deus uno e trino em sua Glória". Para Agamben (2008), porém, a inoperosidade de Deus 5 não significa que a administração divina desapareça do mundo em sua relação de governo dos homens. $\mathrm{O}$ autor argumenta:

Um Deus totalmente ocioso é um Deus impotente, que abdicou de qualquer governo do mundo (...) Para evitar o desaparecimento total de todos os poderes, eles [teólogos] separam-no do seu exercício e afirmam que o poder não desaparece, mas que, simplesmente, deixa de ser exercido, assumindo assim a forma imóvel e resplandecente da Glória (em grego, doxa) (AGAMBEN, 2007, p. 41).

Agamben (2008, p. 265) salienta que "na iconografia do poder (...) essa vacuidade central da Glória, essa intimidade entre majestade e inoperosidade, encontrou um símbolo exemplar (...) na imagem do trono vazio". O vazio do trono é parte integrante da inoperatividade que está no coração da Glória, e que a Glória deve aproveitar para operar. Dito de outro modo, para que

\footnotetext{
${ }^{4}$ Conforme Agamben (2008, p. 331), a Glória "expressa a zona incerta em que se movem aclamações, cerimônias, liturgia e insígnias". Caracteriza, assim, o conjunto de aspectos simbólicos do culto cristão e aquilo que articula a relação entre imanência e transcendência na dualidade complementar da ordem trinitária (PFISTER, 2019).

${ }^{5}$ A inoperosidade divina manifesta-se na tradição judaico-cristã de algumas maneiras: no shabat judaico e na promessa da vida eterna, por exemplo (PFISTER, 2019).
} 
esse poder se mantenha no governo dos homens e a inoperosidade divina seja louvada, é necessário capturar no homem a sua inoperosidade, transformando-a em operatividade. Conforme Pfister (2019, p. 119), "o poder precisa da Glória justamente porque ela vela e ao mesmo tempo captura a inoperosidade essencialmente humana, devotando-a incessantemente ao trabalho, à execução de uma obra, de um dever, de um ofício". É assim, segundo Phelps (2012, p. 1, tradução nossa), "que a inoperatividade é a substância política do Ocidente, o nutriente glorioso do poder".

Agamben (2008, p. 12), desse modo, também identifica o aspecto "glorioso" da teologia cristã com a organização oikonómica, a qual possui na forma aclamatória do "consenso" seu aporte específico e cujo paradigma original se encontra nos tratados medievais e barrocos sobre o governo divino do mundo. Para o autor, o centro da máquina governamental está vazio, e esse é, quiçá, o símbolo mais significativo de poder. É nesse sentido que se argumenta que, da mesma forma que o aspecto glorioso de poder permanece na administração do mundo mesmo com a finitude do projeto oikonómico divino, assim também os aspectos de poder, dominação e controle, agora de maneira gloriosa, permanecem nas organizações flexíveis, na medida em que não há uma ruptura com a burocracia, mas uma adaptação das organizações a uma reestruturação produtiva (PAES DE PAULA, 2002; SILVA 2003).

O aspecto glorioso do poder presente nas organizações flexíveis também se traduz, entre outros aspectos, em sua majestosidade cerimonial e litúrgica. A função das aclamações e da Glória, na forma do consenso, está no centro dos dispositivos políticos dessa sociedade, conforme Agamben (2008).

Si los media son tan importantes en las democracias modernas no se debe, en efecto, sólo a que ellos permiten el control y el gobierno de la opinión pública, sino también y sobre todo a que administran y otorgan la Gloria, aquel aspecto aclamativo e doxiológico del poder que en la modernidad parecía haber desaparecido. La sociedad del espectáculo - si llamamos con este nombre a las democracias contemporáneas - es, desde este punto de vista, una sociedad en la que el poder en su aspecto "glorioso" se vuelve indiscernible de la oikonomía y del gobierno (AGAMBEN, 2008, p. 11).

Com efeito, as organizações flexíveis prezam por "programas de socialização dos indivíduos via treinamento ou aprendizado através do uso de elementos simbólicos" que "reforçam as crenças organizacionais e o espírito de que 'somos um time especial e juntos obteremos o sucesso"' (PRESTES MOTTA, 1993, p. 74). Neste sentido, o symbolic manager encoraja os ritos e celebrações (festas e confraternizações, nomes de time, apelidos, cores ou imagens que representam equipes, etc.) de um subgrupo da organização, procurando relacioná-lo com a cultura da mesma, que não pode ser sobrepujada nesse processo.

Assim, do mesmo modo que Deus dá o livre-arbítrio às suas criaturas, a empresa concede a seus funcionários a liberdade de escolha na ordenação da execução de suas atividades. No entanto, nos dois casos ainda resiste a captura da operatividade em favor da promessa da inoperosidade: há um destino a chegar (paraíso), um trabalho a cumprir, uma ordem a executar, que não se anulam com a concessão dessa liberdade limitada. Desse modo, os dois parecem deixar livre o homem, quando na verdade operam um controle subjetivo muito mais forte, uma vez que em ambos há algo invisível que observa a operação (PAGÈS, BONETTI, GAULEJAC et al., 1993; PRESTES MOTTA, 2001). Se agora não há mais figura formal de controle, a sua contestação também se torna mais complexa: como se desvencilhar de um fantasma?

Para Agamben (2008, p. 7), o paradigma divino de governo dos homens não é tirânico, mas democrático. A partir de Leibniz, o autor explica que "Deus governa a tudo de modo irresistível, mas docemente e sem violência, de maneira que o homem crê seguir sua vontade enquanto executa a de Deus". Analogamente, se estabelece um modelo em que o gerente "governa" seus funcionários por meio de uma solidariedade sutil e imperceptível, como se eles governassem a si mesmos. Nas organizações flexíveis, isso fica evidente na medida em que o governo sobre os homens transcorre não por meio da coerção ou da autoridade hierárquica, mas por uma série de tecnologias de poder relacionados à prática do governo dos homens, dentre as quais o sistema legal, os mecanismos disciplinares e os dispositivos de segurança, capazes de produzir sujeitos governáveis por meio da captura de sua subjetividade (FONTOURA e BIROCHI, 2015; AGAMBEN, 2008).

Conforme a investigação genealógica da teologia da economia e do governo de Agamben (2008, p. 195, tradução livre), as técnicas governamentais de domínio dos homens, que ficarão evidentes nas organizações flexíveis, como veremos a seguir, possuem origem no pastorado cristão, que desenvolve um "governo das almas" e que, "como 'técnica das técnicas', define a atividade da Igreja até o século XVIII, quando se converte no 'modelo' e 'matriz' (...) do governo político". Agamben (2008) afirma que uma das características essenciais do pastorado cristão é o fato de que ele se refere tanto aos indivíduos quanto à 
totalidade, cuidando dos omnes et singulatim (todos e cada um). O pastorado, como técnica governamental, é individualizante e totalizador porque, ao tratar os membros de forma fragmentada, desarticula-os politicamente.

Esse desenraizamento político dos membros no interior das organizações orientadas pelo participacionismo, como as flexíveis, é destacado por Tragtenberg (2005), para quem as técnicas disciplinares de manipulação culpabilizam o indivíduo por aquilo que é produzido em nível social. Tragtenberg cita o uso massivo de gratificações de ordem simbólica, as técnicas de aconselhamento e as consultas individuais que procuram controlar a hostilidade e medir o nível de lealdade do indivíduo em relação à organização. Pode-se observar que essas técnicas guardam estreita semelhança com aquelas utilizadas pelo pastorado cristão para controlar a vida dos fiéis: confissão, aconselhamento, culpabilização pelo ideário do pecado, gratificação simbólica (nesse caso a posteriori, com a imagem do paraíso), dentre outras, as quais são empregadas no sentido de manutenção da ordem. A diferença cabal aqui se dá pelo fato de que na organização flexível isso tudo está "coberto por uma capa de racionalismo e logicidade", o que contribui para a "sacralização da empresa como instituição - ela começa a ter 'função social', aparece como uma família extensa, garantindo a seus membros realização pessoal e satisfação individual", funcionando como o a Igreja e dando um sentido à vida de seus empregados (TRAGTENBERG, 2005, p. 33-34).

Agamben (2008, p. 195, tradução livre) retoma Foucault para demonstrar que um outro aspecto essencial que pastorado cristão e governamento compartilham é "a ideia de uma 'economia', isto é, de uma gestão ordenada segundo o modelo familiar dos indivíduos, das coisas e das riquezas". A manipulação, angústia e culpabilização do indivíduo operada por essa forma de gestão que congrega uma ideia familiar promove uma apatia política nos membros, pois segundo Tragtenberg $(2005$, p. 40) "cada vez que na área do político sois chamados de 'meus filhos', a esfera de vossos direitos políticos desaparece". Essa invasão em dimensões subjetivas e sensíveis dos indivíduos sinaliza uma nova estratégia das organizações flexíveis em relação às burocráticas no que diz respeito à dinâmica de ordenação entre trabalho e pathos.

Como sinalizado, nessa dinâmica gloriosa de captura da inoperosidade ocorre um forte redirecionamento do pathos enquanto administração do prazer e canalização da agressividade para um potencial produtivo. Conforme Prestes Motta (1981, p. 35), neste sentido, "é preciso canalizar todas as forças que possam ser produtivas, e para tanto não basta punir ou reprimir, mas torna-se essencial vigiar de modo discreto e permanente". Essa vigilância permanente constitui, em verdade, um sistema de crenças e um ideal de vida concretizado em regras que não são formais, mas que funcionam como "um mandamento, que tem seu fundamento na onipotência do inconsciente de cada um" (PRESTES MOTTA, 1981, p. 35). Esse sistema de vigilância funciona de maneira semelhante à vigilância divina sobre as criaturas que se dá por meio da onipresença de Deus. Agamben (2008) argumenta que é essa sombra que se impõe e se faz presente, símbolo da Glória, que falta profanar.

\section{SACRALIDADE E ORGANIZAÇÕES BUROCRÁTICAS E FLEXÍVEIS: REFLEXÕES FINAIS}

Este ensaio teórico procurou realizar uma aproximação entre a teologia cristã e a administração, procurando estabelecer relações entre aspectos relativos à teologia cristã e sua ordem trinitária e as características de organizações burocráticas e flexíveis, ao problematizar a ideia de secularização e racionalidade que as atravessa. A proposta não objetivou, contudo, encerrar uma remissão dessas organizações à sua originalidade divina, excluindo-se todas as outras relações que configuraram, ao longo do tempo, suas formas de organizar e as relações de poder e dominação que as perpassam. Objetivou-se, sim, jogar luz sobre as possíveis relações e remissões existentes entre a organização oikonómica divina e as organizações burocráticas e flexíveis.

A partir dessas relações e da observação de um novo tipo de sacralização nestas organizações que, sem romper com o ideário divino, tornam sagrado o poder econômico, o dinheiro, a técnica e a lógica formal sobre tudo o mais, advoga-se pela profanação do sagrado, pela restituição à comunidade humana daquilo que historicamente foi subtraído ao uso comum por meio da sacralização. Entende-se que essa saída pode se dar por meio das reflexões acerca da inoperosidade e sua relação com a política e a estética, que remetem a uma nova possibilidade de uso do prazer, do desejo e do corpo. Neste espaço, procura-se fazer alguns apontamentos sobre esse tema, sem, contudo, esgotar a discussão, na medida em que o próprio conceito de inoperosidade e suas articulações permanecem abertos na obra de Agamben, como convite e tarefa política da geração que vem.

O conceito de inoperosidade é particularmente importante porque faz parte do modo pelo qual o poder glorioso, por meio dos seus dispositivos, lança os homens incessantemente ao trabalho, transformando sua inoperosidade em operatividade 
(AGAMBEN, 2008). Como discutido, esses dispositivos estão disseminados por toda parte nas organizações e na sociedade, inculcando um processo de adestramento da alma dos indivíduos (PRESTES MOTTA, 1981, 2001). Se isso é verdade e estamos sempre transitando entre diferentes dispositivos de poder, pode-se perguntar: se não é possível apagá-los, como desativá-los? Como usá-los de outro modo? (ROSA, 2015).

Para Agamben, não se trata de eliminar, mas de desativar, tornar inoperoso um poder, uma função ou uma operação humana. Essa é a tarefa política da profanação, segundo o autor, que trabalha com o conceito da inoperosidade no sentido de liberação de potencialidades, de possibilidade de restituição ao uso e não necessariamente de desaparições em um registro no arquivo e na memória (PHELPS, 2012; ROSA, 2015). É importante enfatizar que a inoperosidade, aqui, contrapõe-se a uma modelo operativo e produtivo, mas não significa simplesmente o contrário da operatividade, ou inércia, mas uma possibilidade de contemplar o nosso poder, aquilo que se pode ou não fazer, a nossa "potência de não".

A inoperosidade remete-nos à abstenção da finalidade produtiva, a uma liberação da economia e, portanto, a um movimento político que é capturado pela primeira para a ordenação dos corpos de maneira eficaz e para a imposição de um modo de ser no mundo (AGAMBEN, 2008; BÖHM, 2005). A inoperosidade, portanto, potencializa a subversão de movimentos ordinários do corpo ou de gestos que qualificam o ser profissionalmente e "tendem a identificar a natureza humana com a força de trabalho simples" (TRAGTENBERG, 1974, p. 194).

Conforme Agamben (2007), o que se pode fazer, portanto, é um novo uso. No caso do capitalismo e sua(s) forma(s) de organização econômica constituídos como religião, Agamben (2007) defende uma profanação do improfanável como a tarefa política da geração que vem. Para o filósofo italiano, ainda que seja o capitalismo essa religião que a tudo invade num culto incessante, trata-se de buscar a libertação "da asfixia consumista em que estamos metidos", e também, ao mesmo tempo, de afastar-se da sacralização "da razão acima de tudo", chamando atenção "para o impessoal, o obscuro, o pré-individual da vida de cada um de nós" (AGAMBEN, 2007, p. 9).

Para Agamben (2005), seria por meio da política que se poderia pensar em tal perspectiva de livre uso do mundo, dimensão esta que foi sempre escamoteada, seja no pastorado cristão ou seja nas formas de governamento empregadas no âmbito do capitalismo. Böhm (2005) corrobora esse entendimento ao afirmar que o reposicionamento da ideia de organização passa por uma intervenção política, que não se furta de considerar os aspectos político-econômicos e históricos. No sentido de polemizar a ordem dominante, Agamben (2008, p. 371, tradução livre) argumenta que a estética, a qual remete inevitavelmente à esfera profana do prazer, do desejo e do gozo, é precisamente o "preço a pagar para desapegar da teoria da Glória e da esfera da Gewalt [violência], do poder". Também para Rancière (2009, p. 11-12), "hoje em dia, é no terreno estético que prossegue uma batalha ontem centrada nas promessas da emancipação e nas ilusões e desilusões da história", porque os atos estéticos, como configurações da experiência, "ensejam novos modos de sentir e induzem novas formas da subjetividade política".

É importante ressaltar que Agamben e Rancière não se referem aqui a uma ideia moderna de estética, na medida em que recusam a objetividade, a rigidez e a representação autorizada e fechada da arte que se faz nesse sentido. Os dois filósofos, embora partindo de matrizes diferentes, tocam-se na questão política "enquanto potência capaz de desativar dispositivos de dessubjetivação" (MOURA e ALMEIDA, 2014, p. 120). Ambos convergem para a ideia de que esse processo de questionamento de lugares e identidades pré-distribuídas, na medida em que opera desconstruções e intervenções no visível e no dizível e não se relaciona a uma finalidade específica, mas é um meio sem fim ou um meio em si, está emaranhado na questão estética (AGAMBEN, 2008; RANCIÈRE, 2009). Assim, na contemporaneidade, "a arte é a atividade inoperosa por excelência, porque, a partir do momento em que se não restringe a oeuvrer, isto é, a produzir obras, permite escapar a todo fim produtivo imposto pelo capitalismo" (MORAES, 2019, p. 1).

Segundo Rancière (2009, p. 64-65), "a partilha democrática do sensível ${ }^{6}$ faz do trabalhador um ser duplo (...) quando o princípio de uma sociedade bem organizada é que cada um faça apenas uma só coisa, aquela à qual sua 'natureza' o destina". Neste sentido, conforme o autor, a partilha democrática da experiência sensível tira o trabalhador de "seu" lugar, o espaço doméstico do trabalho, e lhe possibilita "estar no espaço das discussões públicas e na identidade do cidadão deliberante". Retomando a ideia de estado "estético" descrita por Schiller em Cartas para a educação estética do homem, Rancière (2009, p. 66) adverte que há uma operação teórica e política que consiste em querer "arruinar, com uma ideia de arte, uma ideia de sociedade fundada sobre a oposição entre os que pensam e decidem e os que são destinados aos trabalhos materiais".

${ }^{6}$ Rancière (2009) considera uma noção específica de estética como distribuição do sensível em que são determinados modos de articulação entre formas de perceber, pensar, produzir e agir. Esse regime de distribuição está relacionado a uma perspectiva política da estética, que se opõe a uma distribuição policial. 
Nesse sentido, as práticas artísticas contemporâneas e suas formas de organização correlatas podem ser um campo de investigação importante daquilo que apontam Agamben (2007) e Rancière (2009). Conforme, Benhamou (2007), Durand (2007) e Bendassolli, Wood Junior, Kirschbaum et al. (2009), o setor cultural possui uma série de características peculiares no que diz respeito ao modo como os indivíduos e grupos se organizam, pois as escolhas das organizações culturais passam por concepções estéticas e artísticas, ao contrário das indústrias tradicionais, em que a racionalidade, a funcionalidade e a busca por eficácia e eficiência direcionam o emprego dos recursos.

Por fim, este ensaio teórico entende ser necessário trazer o pensamento organizacional para a esfera do humano, que admite contradição, que é mutável, que é dual e não una, e que exprime sensibilidade na medida em que não é, e não poderia ser, apenas espiritualidade ou razão. A partir disso, é preciso realizar a tarefa política de pensar as organizações a partir de outras categorias que compreendam também a esfera do sensível, da estética e do prazer, profanando a cisão empreendida desde muito entre logos e pathos. 


\section{REFERÊNCIAS}

ADORNO, T.; HORKHEIMER, M. Dialética do esclarecimento. Rio de Janeiro: Zahar Editores, 1985.

AGAMBEN, G. El Reino y La Gloria: una genealogía de la economía y del gobierno. Homo Sacer II, 2. Buenos Aires: Adriana Hidalgo, 2008.

AGAMBEN, G. Profanações. São Paulo: Boitempo, 2007.

ALBAUM, G.; PETERSON, R. A. Ethical attitudes of future business leaders: Do they vary by gender and religiosity? Business and Society, v. 45, n. 3, p. 300-321, 2006.

ASHFORTH, B. E.; VAIDYANATH, D. Work organizations as secular religions. Journal of Management Inquiry, v. 22, p. 359-370, 2002.

ASHMOS, D. P.; DUCHON, D. Spirituality at work: A conceptualization and measure. Journal of Management Inquiry, v. 9, n. 2, p. 134 145, 2000.

BAZANINI, R.; GIGLIO, E. M. The role of stakeholders in Solomon's Temple: an exploratory study. O\&S - Salvador, v. 24, n. 83 , p. 674 690, 2017.

BÉDARD, R. Los fundamentos del pensamiento y la prácticas administrativas. AD-MINISTER, Medellín, n. 4, p. 80-108, ene-jun, 2004.

BENDASSOLLI, F. et al. Indústrias criativas: definição, limites e possibilidades. RAE - Revista de Administração de Empresas, São Paulo, v. 49, p. 10-18, jan./mar. 2009.

BENHAMOU, F. A economia da cultura. Cotia: Ateliê Editorial, 2007.

BERGER, P. L. Os múltiplos altares da modernidade: rumo a um paradigma da religião numa época pluralista. Petrópolis: Vozes, 2017.

BERNARDELLI, L. V.; MICHELLON, E. O Impacto da Religião no Crescimento Econômico: Uma Análise Empírica para o Brasil em 1991, 2000 e 2010. Estudos Econômicos (São Paulo), v. 48, n. 3, p. 489-523, 2018.

BÖHM, S. Repositioning Organization Theory: Impossibilities and Strategies. Basingstoke: Palgrave, 2005.

CLEGG, S. As Organizações Modernas. Oeiras (PT): Celta Editora, 1998.

COSGEL, M.; MINKLER, L. Religious Identity and Consumption. Review of Social Economy, v. 62, p. 339-350, 2004.

CORRÊA, V. S.; VALE, G. M. V.; CRUZ, M. A. Entrepreneurial Orientation and Religion: The Pastor as an Entrepreneur. Revista de Administração, v. 52, n. 3, p. 330-340, 2017.

CUNHA, J. A. et al. Innovation in a religious environment: establishing an inter-organizational network oriented to the Islamic market. Revista de Administração Mackenzie, v. 17, p. 122-155, 2016.

DUCHON, D.; PLOWMAN, D. A. Nurturing the spirit at work: Impact on work unit performance. Leadership Quarterly, v. 16, p. 807-833, 2005.

DURAND, J. C. Prefácio. In: BENHAMOU, F. A economia da cultura. Cotia: Ateliê Editorial, 2007. p. 11-14.

ENOQUE, A. G.; BORGES, A. F.; BORGES, J. F. Religião e consumo: aspectos conceituais, limites e possibilidades. Farol - Revista de Estudos Organizacionais e Sociedade, Belo Horizonte, v. 2, n. 4, p. 488-532, 2015.
FARIA, J. H.; MENEGHETTI, F. Burocracia como organização, poder e controle. RAE-Revista de Administração de Empresas, São Paulo, v. 51, p. 424-439, 2011.

FINCH-LEES, T.; MABEY, C.; LIEFOOGHE, A. 'In the name of capability': a critical discursive evaluation of competency-based management development. Human Relations, v. 58, p. 1185-1222, 2005.

FOUCAULT, M. A Ordem do Discurso. São Paulo: Loyola, 1996.

FONTOURA, D.; BIROCHI, R. Organizações Flexíveis como Prática de Governamentalidade. In: V COLÓQUIO LATINO-AMERICANO DE BIOPOLÍTICA; III COLÓQUIO INTERNACIONAL DE BIOPOLÍTICA E EDUCAÇÃO; XVII SIMPÓSIO INTERNACIONAL IHU, 2015, São Leopoldo. Anais... São Leopoldo: Unisinos, 2015.

GREY, C.; GARSTEN, C. Trust, control and post-bureaucracy. Organization Studies, v. 22, n. 2, p. 229-249, 2001.

HARRISON, S. H.; ASHFORTH, B. E.; CORLEY, K. G. Organizational sacralization and sacrilege. Research in Organizational Behavior, v. 29, p. 225-254, 2009.

HUBER, G.; GLICK, W. (Ed.). Organizational change and redesign. New York: Oxford, 1995.

IBARRA-COLADO, E. Organization Studies and Epistemic Coloniality in Latin America: Thinking Otherness from the Margins. Organization, v. 13, p. 463-488, 2006.

KELLER, A. C.; SMITH, K. T.; SMITH, L. M. Do gender, educational level, religiosity, and work experience affect the ethical decision-making of U. S. accountants? Critical Perspectives on Accounting, v. 18, n. 3, p. 299-314, 2007.

LUDUEÑA ROMANDINI, F. Capitalismo y secularización. Filosofia Unisinos, v. 12, p. 98-113, maio/ago. 2011.

MARTES, A. C.; RODRIGUEZ, C. Afiliação religiosa e empreendedorismo étnico: o caso dos brasileiros nos Estados Unidos. Revista de Administração Contemporânea, v. 8, n. 3, p. 117-140, 2004.

MARTINEZ, A. L.; COELHO, M. L. B. Tax morals and the Brazilian citizen: an empirical study. Cadernos EBAPE.BR, Rio de Janeiro, v. 17, n. 3, p. 607-622, jul./set. 2019.

MILBANK, J. Teologia e teoria social. São Paulo: Loyola, 1995.

MOLTMANN, J. Trindade e o Reino de Deus: uma contribuição para a teologia. Petrópolis: Vozes, 2000.

MORAES, J. I would prefer not to: sobre o conceito de inoperosidade em Giorgio Agamben e a arte contemporânea. Viso: Cadernos de estética aplicada, v. 13, n. 24, p. 168-192, 2019.

MOURA, A. C.; ALMEIDA, H. T. N. Perspectiva do conceito de político à luz da filosofia de Jacques Rancière e Giorgio Agamben. Cadernos de Ética e Filosofia Política, n. 25, p. 108-123, 2014.

NASCIMENTO, C. G. Ética e cristianismo: a busca de um consenso para o século XXI na concepção de Leonardo Boff. Pensamento \& Realidade, v. 17, p. 113-144, 2005.

NELSON, R. E. Authority, organization, and societal context in multinational churches. Administrative Science Quarterly, v. 38, p. 653-682, 1993. 
NIETZSCHE, F. W. A Gaia Ciência. São Paulo: Companhia das Letras, 2001.

OLIVEIRA, L. L. S.; CORTES, R. X.; BALBINOTTO, G. A economia da religião e seus fundamentos: teste de um modelo de escolha religiosa. Estudos Econômicos, v. 41, n. 4, p. 811-840, 2011.

PAES DE PAULA, A. P. Tragtenberg revisitado: as inexoráveis harmonias administrativas e a burocracia flexível. Revista de Administração Pública, Rio de Janeiro, v. 36, p. 127-144, jan./fev. 2002.

PAGÈS, M. et al. O poder das organizações. São Paulo: Atlas, 1993.

PAIVA, L. E. B. et al. Planned behavior and religious beliefs as antecedents to entrepreneurial intention: A study with university students. Revista de Administração Mackenzie, São Paulo, v. 21, n. 2, eRAMG200022, 2020.

PALMER, I.; BENVENISTE, J.; DUNFORD, R. New Organizational Firms: Toward a Generative Dialogue. Oganization Studies, v. 28, n. 12, p. 1829-1847, 2007.

PARKER, M. Against Management: Organization in the Age of Managerialism. Cambridge: Polity Press, 2002.

PARKER, J. Z.; BAKER, J. What would Jesus buy: American consumption of religious and spiritual material goods. Journal for the Scientific Study of Religion, Malden, v. 46, n. 4, p. 501-517, 2007.

PFISTER, M. Oikonomia trinitária na obra de Giorgio Agamben: entre o reino e a glória, Opus Dei e altíssima pobreza. Campinas: PUC-Campinas, 2019.

PHELPS, H. Performing Profanation: Giorgio Agamben's Non-NonChristianity. Political Theology Network, 27 nov. 2012.

PRESTES MOTTA, F. A propósito da "sociedade organizacional". RAE-Revista de Administração de Empresas, São Paulo, v. 18, p. 71-75, 1978.

PRESTES MOTTA, F. O poder disciplinar nas Organizações Formais. RAE-Revista de Administração de Empresas, São Paulo, v, 21, p. 33-41, out./dez. 1981.

PRESTES MOTTA, F. O que é burocracia? São Paulo: Editora Brasiliense, 1991.

PRESTES MOTTA, F. Controle Social nas Organizações. Revisitado por Isabella F. F. Gouveia de Vasconcellos e Thomaz Wood Junior. RAE-Revista de Administração de Empresas, São Paulo, v. 33, p. 68-87, set./out. 1993.

PRESTES MOTTA, F. A organização como religião laica. O\&S - Salvador, v. 8, n. 22, p. 1-23, 2001.

RANCIÈRE, J. A partilha do sensível: estética e política. São Paulo: EXO experimental org.; Ed. 34, 2009.
RAMOS, A. G. A Sociologia de Max Weber (sua importância para a teoria e prática da administração). Revista do Serviço Público - textos históricos, Brasília v. 57, p. 267-282, abr./jun. 2006.

ROSA, A. Do conceito de inoperosidade para a potência de agir em Agamben. Seara Filosófica, n. 11, p. 21-34, 2015.

SERAFIM. M. C.; ANDION, C. Capital espiritual e as relações econômicas: empreendedorismo em organizações religiosas. Cadernos EBAPE.BR, Rio de Janeiro, v. 8, n. 3, p. 564-579, 2010.

SERAFIM, M. C.; MARTES, A. C.; RODRIGUEZ, C. "Segurando na mão de Deus": organizações religiosas e apoio ao empreendedorismo. RAE-Revista de Administração de Empresas, São Paulo, v. 52, n. 2, p. 217-231, 2012.

SERAFIM, M.; FEUERSCHÜTTE, S. G. Movido pelo transcendente: a religiosidade como estímulo ao "espírito empreendedor". Cadernos EBAPE.BR, Rio de Janeiro, v. 13, n. 1, p. 165-182, 2015.

SILVA, R. C. Controle organizacioanal, cultura e liderança: evolução, transformações, e perspectivas. Revista de Administração Pública, v. 37, n. 4, p. 797-816, 2003.

SOUSA, E. S. et al. The influence of religious beliefs on entrepreneurial intention: an analysis from the perspective of the Theory of Planned Behavior. Cadernos EBAPE.BR, Rio de Janeiro, v. 18, n. 1, jan./mar. 2020.

SOUTO, C. A. T. Nietzsche e Foucault: da morte de Deus à morte do homem. SABERES, Natal, v. 1, n. 6, p. 129-141, fev. 2011.

SPICER, A.; ALVESSON, M.; KARREMAN, D. Critical Performativity: The Unfinished Business of Critical Management Studies. Human Relations, v. 62, n. 4, p. 537-560, 2009.

SPICER, A.; ALVESSON, M.; KARREMAN, D. Extending critical performativity. Human Relations, v. 69, n. 2, p. 225-249, 2016.

STEINGARD, D. S. Spiritually-informed management theory - Toward profound possibilities for inquiry and transformation. Journal of Management Inquiry, v. 14, n. 3, p. 227-241, 2005.

TRACEY, P. Religion and Organization: A Critical Review of Current Trends and Future Directions. The Academy of Management Annals, v. 6, n. 1, p. 87-134, 2012.

TRAGTENBERG, M. Burocracia e ideologia. São Paulo: Ática, 1974.

TRAGTENBERG, M. Administração, Poder e Ideologia. 3. ed. rev. São Paulo: Editora UNESP, 2005.

VASCONCELOS, A. F. The Spiritually-Based Organization: A Theoretical Review and its Potential Role in the Third Millennium. Cadernos EBAPE.BR, Rio de Janeiro, v. 13, n. 1, p. 183-183, 2015.

WALKER, A. G.; SMITHER, J. W.; DEBODE, J. The Effects of Religiosity on Ethical Judgments. Journal of Business Ethics, v. 106, n. 4, p. 437-452, 2012. 
Aline Van Neutgem

ORCID: https://orcid.org/0000-0002-6307-4205

Mestra em Administração pela Universidade Federal de Santa Catarina (UFSC); Pesquisadora associada ao Observatório da Realidade Organizacional (UFSC), Florianópolis - SC, Brasil. E-mail: aline.neutgem@gmail.com

Eloise Helena Livramento Dellagnelo

ORCID: https://orcid.org/0000-0001-7586-0302

Doutora em Engenharia de Produção pela Universidade Federal de Santa Catarina (UFSC); Professora no Programa de Pós-Graduação em Administração da Universidade Federal de Santa Catarina (UFSC), Florianópolis - SC, Brasil. E-mail: eloiselivramento@gmail.com 